\title{
KEGGIN HETEROPOLY ACIDS AS AN EFFICIENT CATALYSTS FOR PHOTOCATALYTIC OXIDATION OF AROMATIC ALDEHYDES
}

\author{
F.Z. Yehia ${ }^{1}$, G. M. Elkady² A. H. Mady*, E. M. Elnaggar², A. M. Hussein ${ }^{1}$ \\ ${ }^{1}$ Department of Petrochemicals, Egyptian Petroleum Research Institute (EPRI), Nasr City, Cairo, Egypt, \\ Postal Code 11727. \\ ${ }^{2}$ Department of Chemistry, Alazhar University, Nasr City, Cairo, Egypt. \\ *amr_mady2005@yahoo.com
}

\begin{abstract}
Photocatalytic oxidation of aromatic aldehydes to related carboxylic acids was investigated in the presence of some Keggin heteroploy acids as phosphomolybdic acid $\mathrm{H}_{3} \mathrm{PMo}_{12} \mathrm{O}_{40}(\mathrm{PMo})$, silicotungestic acid $\mathrm{H}_{4} \mathrm{SiW}_{12} \mathrm{O}_{40}(\mathrm{SiW})$ and phosphotungstic acid $\mathrm{H}_{3} \mathrm{PW}_{12} \mathrm{O}_{40}(\mathrm{PW})$. Keggin acids can catalyze the oxidation of 4carboxybenzaldehyde (4-CBA) and p-tolualdehyde ( $p$-Tol) under homogeneous reaction. Also, for additional studies, we reconnoitered the application of Keggin catalyst in the presence of persulfate (PS) as oxidizing agent. Our results showed that in the presence of PS and (6 watt)UV light, the most active catalyst among the used Keggin acids is the phosphomolybdic acid (80.9\% yield) due to the high oxidative ability of molybdenum . The effects of catalyst concentration, time and oxidant load have been studied. The mechanistic aspects of the reaction also have been discussed.
\end{abstract}

Keywords Keggin heteropoly acid, photocatalytic oxidation, aromatic aldehyde, persulfate.

\section{INTRODUCTION}

The oxidation of aromatic aldehydes to their corresponding carboxylic acids has been a remarkable importance in industrial chemistry as the obtained products are used in several industrial applications as cosmetics, preservatives materials, pharmaceuticals, beverages and a wide variety of organic chemicals [1-3]. The oxidations of aromatic aldehydes using $\mathrm{KMnO} 4$ have been mentioned in many reports [4-6]. Also, Oxone was used to achieve such transformation in the help of other catalysts [7-8], but these conventional oxidants produce many amounts of undesirable waste with very low product yield [9]. So, the introduction of new and efficient catalysts is in much demand.

Photocatalysis is astonishing in many fields including water treatment, selective organic synthesis, air cleaning, hydrogen production and disinfection applications [1012]. In the last two decades, green photocatalysts as polyoxometalates (POMs) have been introduced and widely used which they have similarity in the photochemical characteristics and general properties of the semiconductor photocatalyst. Among these POMs, Keggin heteropoly acids (HPAs) and its derivatives have been extensively used as oxidation catalysts and acid for a numerous of industrial applications and many organic syntheses [13-18].

In homogeneous catalysis, POMs have been used broadly in liquid phase because of their high solubility in the polar solvents. So, in the assisted photo oxidation reactions they can be activated using UV light [19-20]. POMs have high photocatalytic performance which is based on the transfer of an electron from the highest occupied molecular orbital(HOMO)to the lowest unoccupied molecular orbital (LUMO) and this action create positive charged hole in HOMO orbital, the POM photocatalytic activity is based on the created hole which has strong oxidative property [21]. POMs have some advantages as a multi-electron redox processes which attributed to the huge number of metal centers exist in the structure of POMs [22], a strong light absorption in the spectral range of 200-500 nm due to the O/M ligand-tometal charge transfer absorption bands [23] and 
the reduced POM can be re-oxidized in the presence of persulfate, this make the system reliability is maintained even when hard conditions are employed due to the absence of any organic ligands [23].

The objective of this paper is to extending the applications of Keggin catalyst to oxidize some aromatic aldehydes (4-CBA \& p-Tol) to corresponding carboxylic acids in presence of low power UV light and persulfate as oxidant. The catalytic photo-assisted activities of some Keggin types as $\mathrm{H}_{3} \mathrm{PW}_{12} \mathrm{O}_{40}, \mathrm{H}_{3} \mathrm{PMo}_{12} \mathrm{O}_{40}$ and $\mathrm{H}_{4} \mathrm{SiW}_{12} \mathrm{O}_{40}$ have been examined under gentle experimental conditions.

\section{EXPERIMENTAL}

\subsection{Materials}

$\mathrm{Na}_{2} \mathrm{MoO}_{4}$ (Aldrich 98+\%), $\mathrm{Na}_{2} \mathrm{WO}_{4} \cdot 2 \mathrm{H}_{2} \mathrm{O}$ (Aldrich98+\%), $\mathrm{Na}_{2} \mathrm{SiO}_{3} \cdot 9 \mathrm{H}_{2} \mathrm{O}$ (Aldrich $98+\%$ ), $\mathrm{H}_{3} \mathrm{PO}_{4}$ (JanssenChimica 85\%), $\mathrm{Na}_{2} \mathrm{HPO}_{4} \cdot 12 \mathrm{H}_{2} \mathrm{O}$ (Aldrich 98+\%),concentrated $\mathrm{HCl}$ (Merck 37\%), diethyl ether (75 mL Merck 99.7+\%), concentrated $\mathrm{HNO}_{3}$ (Merck 65\%), $\mathrm{H}_{2} \mathrm{SO}_{4}$ (Aldrich 95-98\%), 4-carboxy benzaldehyde (Merck $\geq 99 \%$ ), sodium peroxodisulphate $\mathrm{Na}_{2} \mathrm{~S}_{2} \mathrm{O}_{8}$ (panreac quimica sau 98+\%), 4methyle benzaldehyde (Merck $\geq 97 \%$ ).

\subsection{Catalyst preparation}

The Keggin heteropolyacids were obtained through the 'etherate method' [24].

\subsubsection{Synthesis of the phosphomolybdic Keggin acid $\mathrm{H}_{3} \mathrm{PMo}_{12} \mathrm{O}_{40}$}

In brief $45.55 \mathrm{~g}$ of $\mathrm{Na}_{2} \mathrm{MoO}_{4}$ were dissolved in $100 \mathrm{ml}$ of distilled water (DW). 50 $\mathrm{ml}$ of $37 \% \mathrm{HCl}$ and $5 \mathrm{~mL}$ of concentrated $\mathrm{H}_{3} \mathrm{PO}_{4}$ were added. By transferring this acidified solution to dropping funnel with diethyl ether under shaking, the lowest formed layer has been transferred to another dropping funnel with $\mathrm{HCl}$ and diethyl ether and this process has been repeated three times. The resulting solution was evaporated, and by using Buchner funnel the formed crystals were filtered [25].

\subsubsection{Synthesis of the phosphotungstic Keggin acid $\mathrm{H}_{3} \mathrm{PW}_{12} \mathrm{O}_{40}$}

In brief, $50 \mathrm{~g} \mathrm{Na} \mathrm{WO}_{4} \cdot 2 \mathrm{H}_{2} \mathrm{O}$ dissolved in 100mlDW; then $11 \mathrm{~g} \mathrm{Na}_{2} \mathrm{HP}_{4} \cdot 12 \mathrm{H}_{2} \mathrm{O}$ was slowly added to this solution. $\mathrm{HCl}$ and diethyl ether were added and processed as mentioned above in case of phosphomolybdic Keggin acid $\mathrm{H}_{3} \mathrm{PMo}_{12} \mathrm{O}_{40}$ [26].

\subsubsection{Synthesis of the silicotungstic Keggin acid $\mathrm{H}_{4} \mathrm{SiW}_{12} \mathrm{O}_{40}$}

In brief, $50 \mathrm{~g} \mathrm{Na}_{2} \mathrm{WO}_{4} \cdot 2 \mathrm{H}_{2} \mathrm{O}$ dissolved in100 ml DW; then $4 \mathrm{~g} \mathrm{Na}_{2} \mathrm{SiO}_{3} \cdot 9 \mathrm{H}_{2} \mathrm{O}$ was slowly added to this solution. $\mathrm{HCl}$ and diethyl ether were added and processed as mentioned above [26].

\subsection{Photoreactor}

A glass reactor with internal UV lamp (6 watt) as a light source inside quartz jacket. The temperature of the reaction was maintained at $25 \pm 1^{\circ} \mathrm{C}$ by using an external cooling coil. The lamp putted away from the sample surface by 3 $\mathrm{cm}$.

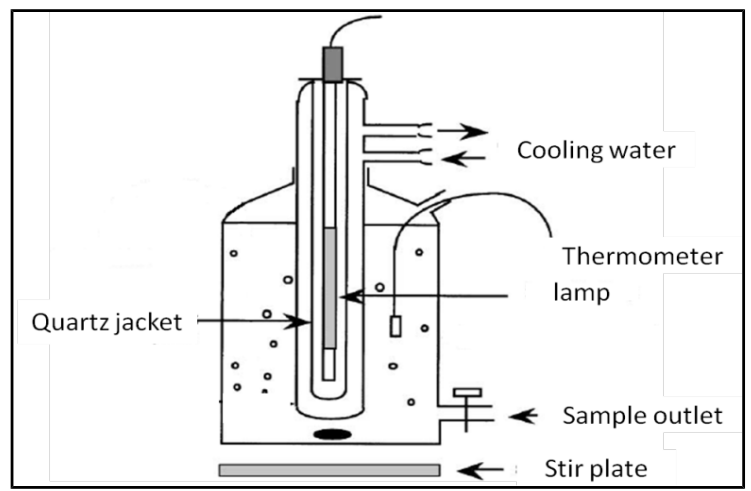

Scheme1, 1Photoreactor

\subsection{Characterization}

The prepared catalysts were characterized via the following analytical techniques. XRD patterns were record on a XPERT X-ray diffractometer using $\mathrm{CuK} \alpha$ radiation $(\lambda=$ $0.1542 \mathrm{~nm})$. The $2 \Theta$ range was recorded between $10 \Theta$ and $80 \Theta$. Fourier Transformed Infra Red spectra (FTIR) were recorded in the transmission mode using a Nicolet IS-10, the spectra were recorded between 400 and 4000 $\mathrm{cm}^{-1}$. FT-Raman spectroscopy was carried out by using a model XploRA plus Raman spectrometer, in the range200 and $2000 \mathrm{~cm}^{-1}$.

\subsection{Catalytic reaction}


KEGGIN HETEROPOLY ACIDS AS AN EFFICIENT CATALYSTS ...

The photocatalytic oxidation reactions were carried out in the presence of $\mathrm{H}_{3} \mathrm{PMo}_{12} \mathrm{O}_{40}(10$ $\mathrm{mg} / \mathrm{l})$ as catalyst and the molar ratio of 4-CBA to $\mathrm{PS}$ is $1: 1.2$, a mixture of $\mathrm{CH}_{3} \mathrm{CN}$ and $\mathrm{H}_{2} \mathrm{O}$ (40:60) has been used as solvent. At first the mixture was stirred in dark for 30 minutes so, prior to photoactivation (by applying UV light 6 Watt), preassociation equilibrium was formed during the substrate adsorption process in the dark.

\subsection{High performance liquid chromatography (HPLC)}

The products of the catalytic oxidation of aromatic aldehydes were monitored by HPLC analysis. HPLC system used equipped with a sample injector, a pump (waters 515), and UV/Visible detector waters 2489. System was controlled by milleniumv ${ }^{\circledR} 32$ chromatography manager waters, USA. X-bridge c18 $(0.5 \mu \mathrm{m}$, $6.4 \mathrm{~mm} \times 250 \mathrm{~mm}$ ) column was used. The mobile phase was consisted of an acetonitrile/water in the ratio of 35:65 with $1 \mathrm{ml} / \mathrm{min}$ as a flow rate and wave length equal $254 \mathrm{~nm}$. Detection wave length for products was fixed after examination of 3D plot (wavelength, intensity and time).

\section{RESULTS AND DISCUSSION}

The conversion of 4-CBA to Terephthalic acid was very simplistic in the presence of catalyst, oxidant and UV lamp. 14\% yield of corresponding acid was obtained by only UV irradiation (without using oxidant and catalyst). While, in absence of catalyst and presence of oxidant $20 \%$ yield of corresponding acid was obtained.

\subsection{Catalyst Characterization}

The XRD patterns of the catalysts are shown in Fig.1. The XRD pattern of PW show sharp diffraction peaks around $10.2 \Theta, 20.6 \Theta$, $25.2 \Theta$ and $34.7 \Theta$ in Fig. 1(a), PMo show diffraction peak at $10.3 \Theta, 19.5 \Theta, 28.4 \Theta$ and $36.7 \Theta$ in Fig. 1(b), and the SiW show diffraction peaks at $8.1 \Theta, 22.5 \Theta, 27 \Theta$ and $34.7 \Theta$ inFig.1(c); the result revealed that PW, PMo and SiW possessed Keggin structure [2628].

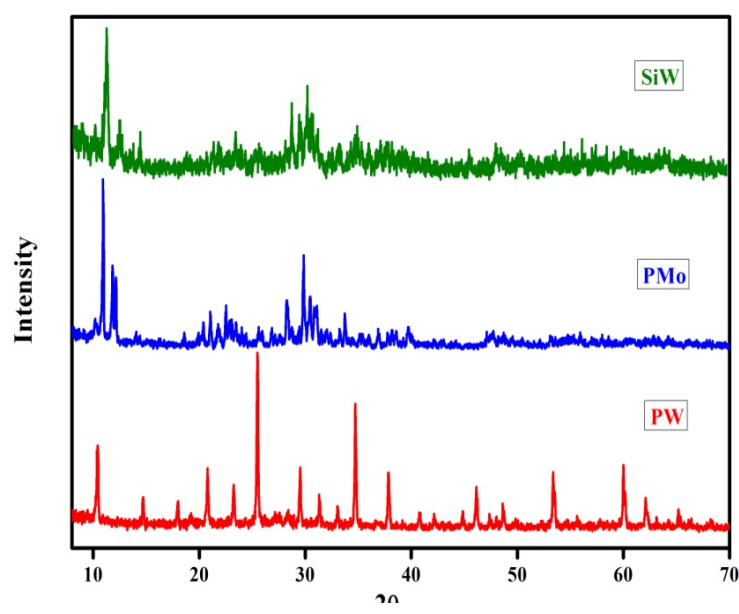

Fig.1. XRD patterns of PW(a), PMo(b), and SiW(c).

FTIR spectra of the catalysts are shown in Fig.2. The structure of the $\mathrm{PW}_{12} \mathrm{O}_{40}$ anion and $\mathrm{PMo}_{12} \mathrm{O}_{40}$ anion consists of a $\mathrm{PO}_{4}$ tetrahedron surrounded by four $\mathrm{W}_{3} \mathrm{O}_{9}$ groups or four $\mathrm{Mo}_{3} \mathrm{O}_{13}$ formed by edge sharing octahedral respectively. These groups are connected each other by corners sharing oxygen atoms [29]. The fingerprint region for these compounds appears between 1100 and $700 \mathrm{~cm}^{-1}$ which give four types of stretching bands. The absorption band for $\mathrm{P}-\mathrm{O}$ is $\left(1080 \mathrm{~cm}^{-1}\right)$, beside the stretching band of $\mathrm{W}=\mathrm{Oat}\left(990 \mathrm{~cm}^{-1}\right)$. The two peaks at810 and $910 \mathrm{~cm}^{-1}$, ascribed to two types of W-O-W [30-31]. In case of PMo, The peaks at 870 and the wide band cantered at ca.790 $\mathrm{cm}^{-1}$ [32] attributable to two types of Mo O Mo units are also present [33]. The FTIR spectra of $\mathrm{SiW}_{12}$ spectrum presents five characteristic vibration modes located at 780, 890, 930, 980, and1020 $\mathrm{cm}^{-1}$. The bands at 780 and 890 $\mathrm{cm}^{-1}$ correspond to stretching of W O W chains, those at $930 \mathrm{~cm}^{-1}$ and $980 \mathrm{~cm}^{-1}$ to Si O and W O stretching's, respectively [34]. The $1020 \mathrm{~cm}^{-1}$ band has been previously observed, however its assignment is unknown [35] and it could be attributed to an impurity adsorbed on the acidic sites of the catalyst [33]. 


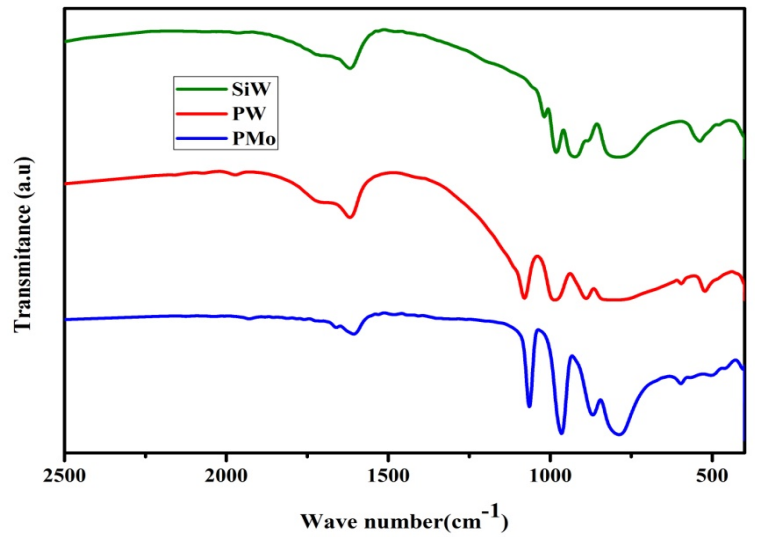

Fig. 2. FTIR spectra of PW, PMO and SiW.

Raman spectrum of PW reported in Fig. 3, shows bands at 1010, $990 \mathrm{~cm}^{-1}$ corresponding to symmetric and asymmetric stretching modes, respectively. The bands at 900 and $880 \mathrm{~cm}^{-1}$ are assigned to $\mathrm{W}-\mathrm{O}-\mathrm{W}$ asymmetric stretching. Waker band at $550 \mathrm{~cm}^{-1}$ assigned to bridging W-O-W asymmetric stretching vibration modes. The group band at $250 \mathrm{~cm}^{-1}$ assigned to W O bending [36]. Raman spectrum of PMo, reported in Fig. 3, showed bands at 983 and $995 \mathrm{~cm}^{-1}$ that are assigned to asymmetric and symmetric stretching of terminal oxygen $\mathrm{Mo}=\mathrm{O}$. The weak band at $882 \mathrm{~cm}^{-1} \mathrm{can}$ be assigned to Mo $\mathrm{O}$ Mo asymmetric stretching, whereas the band at $603 \mathrm{~cm}^{-1}$ to a combined stretching and bending of the Mo-O-Mo bonds [37-38]. The Raman vibrational modes of SiW typically assigned to the Keggin anion are those located at 1019, 981, 927, $881 \mathrm{~cm}^{-1}$, attributed to symmetrical and asymmetrical stretching $\mathrm{W}=\mathrm{O}$ and $\mathrm{W}-\mathrm{O}-\mathrm{W}$ modes [39].

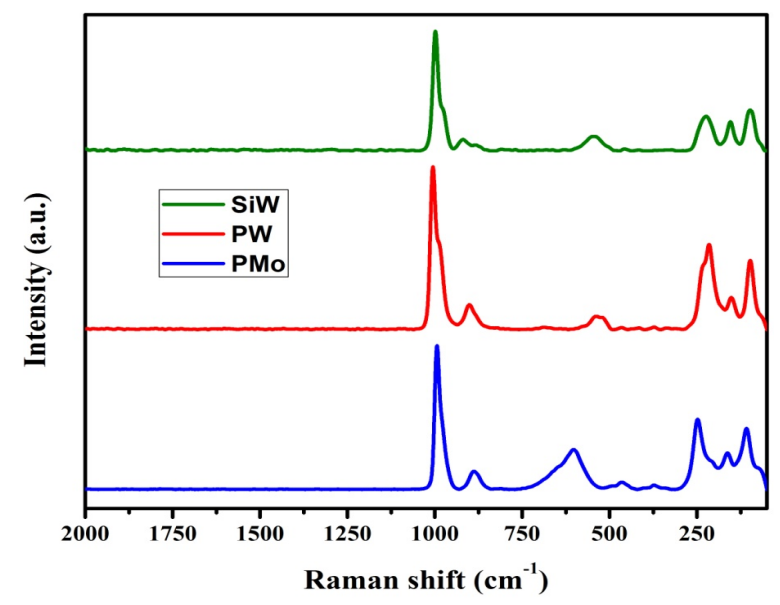

Fig. 3. Raman spectra of: PW, SiWand PMo.

\subsection{Reaction optimization}

\subsubsection{Effect of catalyst dose}

The conversions of 4-CBA to Terephthalic acid (TA) was investigated in solutions with different catalyst concentrations (10 to $40 \mathrm{mg} / \mathrm{l}$ ) as shown in Fig.4. The results show that the highest yield was obtained by using $10 \mathrm{mg} / \mathrm{l}$ catalyst concentration, and any further increasing of the catalyst concentration decrease the yield of TA. The yield of TA reached $80.9 \%$ after $3 \mathrm{~h}$, in the same time when $40 \mathrm{mg} / \mathrm{l}$ was used, the yield was $67.3 \%$. These data demonstrate that the photocatalytic activity of phosphomolybdic acid is related to the concentration, and suggest that in higher concentrations of catalyst, the light dispersion can occur leading to decrease of the photo activity [40] and also may be oxidize Terephthalic acid - corresponding acid -due to the large number of molybdenum atoms which provides many sites on the oval shape of the molecule which tend to render the catalyst effective, which increase the oxidation power [9].

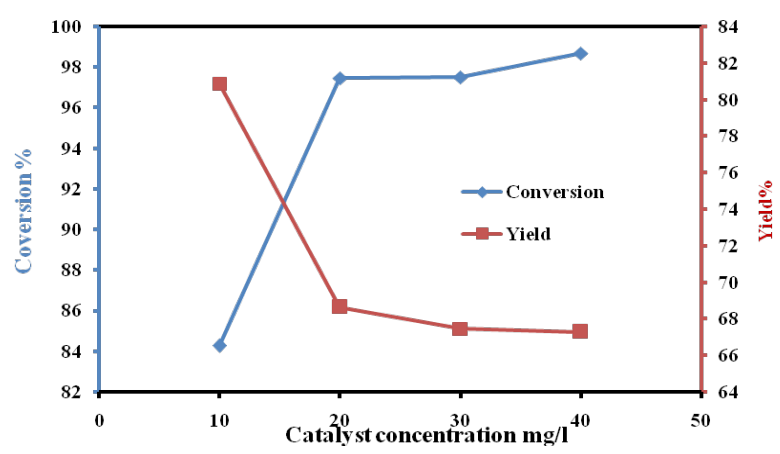

Fig.5. Effect of PS dose on the photoxidation of 4CBA to TA, in presences of $10 \mathrm{mg} / \mathrm{l}$ $\mathrm{H}_{3} \mathrm{PMo}_{12} \mathrm{O}_{40}$ and UV lamp (6 Watt) at $3 \mathrm{~h}$.

\subsubsection{Effect of reaction time}

The effect of reaction time on the yield percent of carboxylic acids (Terephthalic acid) in the photocatalytic oxidations of 4-CBA at the other stage was studied. All of the studies were performed with the best concentration of catalyst $(10 \mathrm{mg} / \mathrm{l})$. The results are shown in Fig.6showed that the yield percent of the product increased with increases in the $n$ reaction time up to 3 hours. 
KEGGIN HETEROPOLY ACIDS AS AN EFFICIENT CATALYSTS ...

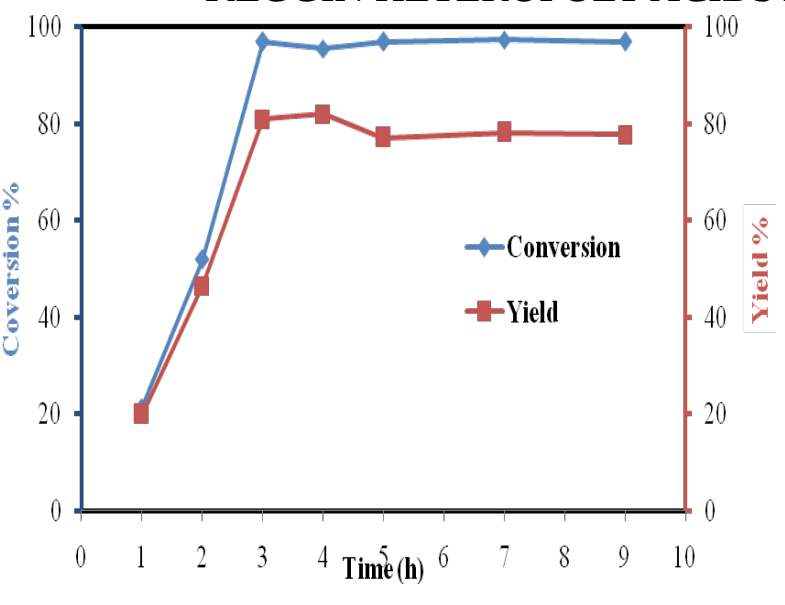

Fig.6. Effect of time on the photoxidation of 4CBA to $T A$, in presences of $10 \mathrm{mg} / \mathrm{l}$ $\mathrm{H}_{3} \mathrm{PMo}_{12} \mathrm{O}_{40}, 20 \mathrm{mg} / \mathrm{l} \mathrm{PS}$ and UV lamp (6 Watt).

The catalytic photo oxidative of pTolualdehyde was studied under the optimum conditions (catalyst $10 \mathrm{mg} / \mathrm{l}$, UV lamp 6 Watt and time $3 \mathrm{hr}$ ) and the results shows that the percent of yield of Terephthalic acid has been dropped to $25.23 \%$ compared with 4-CBA $(80.9 \%)$ as shown in Fig. 7 , this due to formation of another type of acids like p-toluic acid and 4-CBA as by-products.

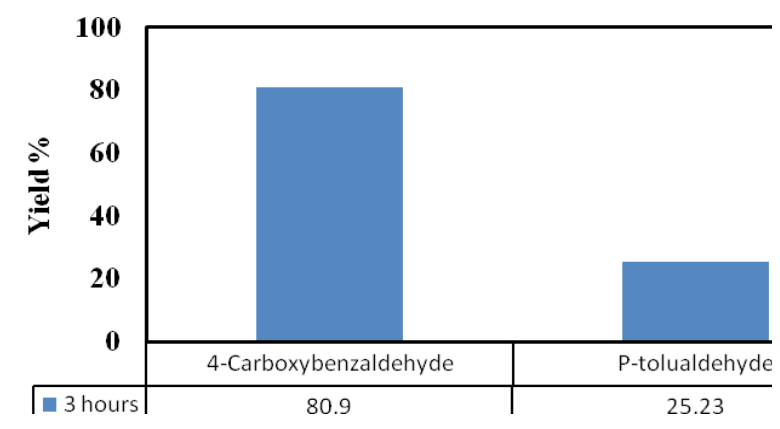

Fig.7. Effect of $10 \mathrm{mg} / \mathrm{l} \mathrm{H}_{3} \mathrm{PMo}_{12} \mathrm{O}_{40}$ on the photoxidation of different types of aldehyde 4-Carboxybenzaldehyde and $p$ tolualdehyde to terephtalic acid, in presences of $20 \mathrm{mg} / \mathrm{l} \mathrm{PS}$ and UV lamp (6 Watt).

\subsubsection{Effect of different types of POM.}

POMs have Oxidative properties which depend on both the central atom and the nature of ligands. It has been established that both the composition of POMs and the nature of counteractions have an influence on the redox properties [41-43]. The oxidative ability decreases in the order $\mathrm{VO}^{-1}>\mathrm{MoO}_{4}{ }^{-2}>\mathrm{WO}_{4}{ }^{-2}$ and HPV > HPMO > HPW. The potential of HPA affected by the central atom of the constant oxidation statevia the change of the polyanion charge [44]. By increasing the anion charge the oxidation potential of HPA falls in the order $\mathrm{PW}_{12} \mathrm{O}_{40}{ }^{-3}(0.15 \mathrm{~V})>\mathrm{Si} \mathrm{W}_{12} \mathrm{O}_{40}{ }^{-3}(-0.05$ $\mathrm{V})$.A sequence of polyoxometalates was proposed according to their decreasing capability of reduction, based on the values of their oxidation potential[45]as shown in Fig.8:

$\mathrm{H}_{3} \mathrm{PMo}_{12} \mathrm{O}_{40}>\mathrm{H}_{3} \mathrm{PW}_{12} \mathrm{O}_{40}>\mathrm{H}_{4} \mathrm{SiW}_{12} \mathrm{O}_{40}$

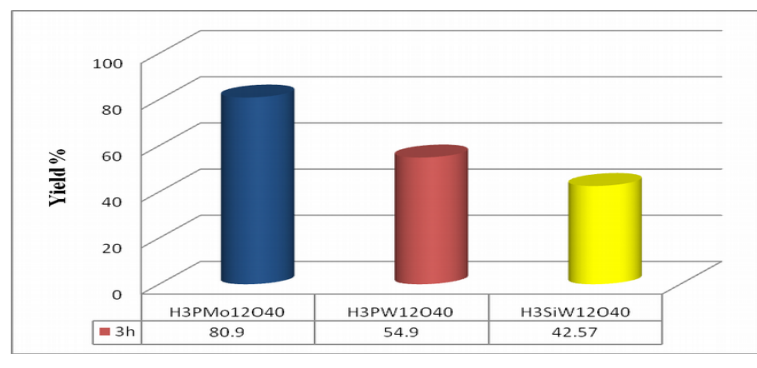

Fig.8. Effect of different types of POM on the photoxidation of 4-CBA to corresponding acid, in presences of $10 \mathrm{mg} / \mathrm{l}$ catalyst, 20 mg/l PS and UV lamp (6 Watt).

\subsection{Reaction mechanism}

POMs have received attention as photochemically active materials. Many of POMs, such as $\mathrm{H}_{4} \mathrm{SiW}_{12} \mathrm{O}_{40}{ }^{4-}, \mathrm{H}_{3} \mathrm{PW}_{12} \mathrm{O}_{40}{ }^{3-}$ and $\mathrm{H}_{3} \mathrm{PMo}_{12} \mathrm{O}_{40}{ }^{3-}$, show similarity in the photochemical characteristics of the semiconductor photocatalyst. It is well known that POMs considered powerful oxidizing reagents by irradiating with visible and UV light which leads to oxidize a huge number of organic compounds.

POMs have photochemistry which can be represented by the following photocatalytic cycle. The POM can be photoexcited ( $\left.\mathrm{POM}^{*}\right)$ when exposed to UV irradiation, by electron transfers from HOMO to LUMO orbital leading to the creation a hole in HOMO orbital. The hole has strong oxidative properties which able to oxidize the aromatic aldehyde resulting in the multi electron reduction of $\mathrm{POM}^{\mathrm{n}}$ Accumulated electron on POM can be reoxidized by electron acceptors, such as various oxidant $\left(\mathrm{e}, \mathrm{g}, \mathrm{SO}_{4}{ }^{-}, \cdot \bullet \mathrm{OH}\right.$ and $\left.\mathrm{O}_{2}{ }^{\bullet}\right)$ which came from water and persulfate which foolproof oxidant, and return the $\mathrm{POM}^{\mathrm{n}}$ to their 
original oxidation state (POM).Thus, they complete a full photocatalytic cycle. The proposed photocatalytic cycle of POMs, which is similar to the familiar photocatalytic cycle of semiconductor photocatalysts [46-51] is shown in Scheme 2.

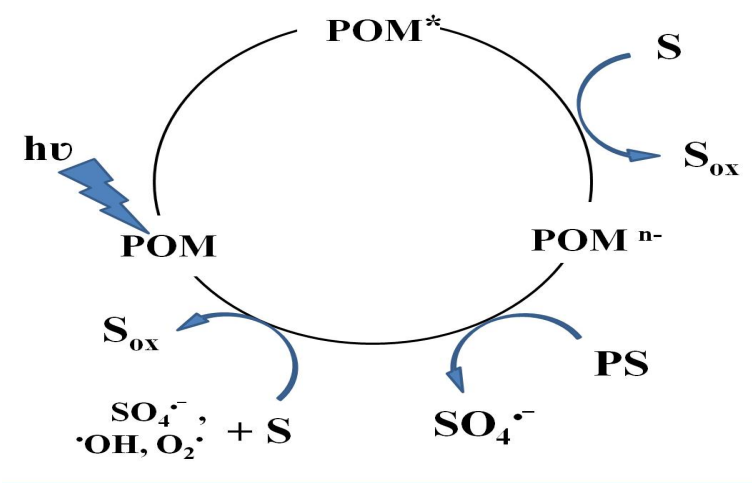

Scheme 2. The photocatalytic cycle of a polyoxometalate (POM). POM*= Photoexcited POM, POM ${ }^{\mathrm{n}-}=$ Reduced POM,PS $=$ Persulfate, $S=$ Organic substrate, $S_{o x}=$ Oxidized substrate.

\section{CONCLUSION}

The present study exhibit the photocatalytic activity of Keggin-types HPA catalysts for the oxidation of aromatic aldehydes in presence of persulfate as oxidant in homogeneous conditions. Optimum conditions have been obtained, and the results revealed that the catalyst concentration, type of addenda atom and UV light are important factors. The importance of this study with easily prepared and inexpensive catalysts essentially lies in the fact that their use would show the way to an alternative technology for the other systems and other aromatic and aliphatic aldehydes, which are of important in nanotechnology, and many industrial fields with advantages from the attitude of the environmental care. In addition, simple procedure and experimental set up makes this method a valuable addition to the current methodologies.

\section{REFERENCES}

[1] Tian, Q., Shi, D., Sha, Y. $\mathrm{CuO}$ and $\mathrm{Ag}_{2} \mathrm{O} / \mathrm{CuO}$ catalyzed oxidation of aldehydes to the corresponding carboxylic acids by molecularoxygen, Molecules. 2008, 13, 94857.

[2] Chumbhale,V. R., Paradhy, S. A., Anilkumar, M., Kadam, S.T., Bokade, V. V. Vapour phase oxidation Of acetophenone to benzoicacid over binary oxides of V and Mo. Chem. Eng. Res. Des. 2005,83, 75-80.

[3] Yuan, Z.H., Chen, B. Z., Zhao, J. S. Controll ability analysis for the liquid phase catalytic oxidation of toluene to benzoic acid. Chem. Eng. Sci. 2011,66, 5137-47.

[4] Choudhary, A. R., Dumbre, D. K.,Narkhede, V. S. Solvent free oxidation of aldehydes to acids by TBHP using environmental friendly $\mathrm{MnO} 4-$ exchanged Mg Alhydrotalcite catalyst. J. Chem. Sci. 2012,124, 835-9.

[5] Jursic, B. Surfactant assisted permanganate oxidation of aromatic compounds. Can. J. Chem. 1989,67, 1381-3.

[6] Wiberg, K. B., Free man, F. Kinetics of the base catalyzed permanganate oxidation of benzaldehyde. J. Org. Chem. 2000, 65, 573-6.

[7] Travis, B. R., Sivakumar, M., Hollist, G. O., Borhan, B. Facile oxidation of aldehydes to acids and esters with oxone. Org. Lett. 2003,5, 1031-4.

[8] Sukriti, S., Anjali, P. Journal of the Taiwan Institute of Chemical Engineers.2015,52, 120 126.

[9] Larkin J. The role of catalysts in the air oxidation of aliphatic aldehydes. J. Org. Chem.1990, 55, 1563-8.

[10] Fatemeh, F. B., Majid, M. H., Soheyla, M. Preyssler Anion as a Green and Eco-friendly Catalyst for Photocatalytic Oxidation of Aromatic Aldehydes. Synthesis and Reactivity in Inorganic. Metal-Organic, and Nano-Metal Chemistry. 2009, 39, 746-750.

[11] Mills, A., Hunte, L. S. An overview of semiconconductor photocatalysis.J. Photochem. Photobiol. A: Chem., , 1997, 108,1-135.

[12] Carp, O., Huisman, C. L., Reller, A. Photoinduced reactivity of titanium oxide. Prog. Solid State Chem. 2004, 32(1-2), 33-177. 
KEGGIN HETEROPOLY ACIDS AS AN EFFICIENT CATALYSTS ...

[13] Tanielian, C., Seghrouchni, R., Schweitzer, C. Polyoxometalate sensitization inmechanistic studies of photochemical reactions: The decatungstate anion as a reference sensitizer for photoinduced free radical oxygenationsof organic compounds. J. Phys. Chem: A.2003, 107(8), 1102-1111.

[14] Yamase, T., and Ishikawa., E. Photochemical self-assembly reaction of $\beta$-[Mo8O26]4- to mixed-valence cluster $\left[\mathrm{Mo}_{37} \mathrm{O}_{112}\right]^{26-}$ in aqueous media.Langmuir.2000, 16(23), 9023-9030.

[15] Houskova, V., Stengl, V., Bakardjieva, S., and Murafa, N. Photoactive materials prepared by homogeneous hydrolysis with thioacetamide: Part2- $\mathrm{TiO}_{2} / \mathrm{ZnO}$ nanocomposites. J .Phys. Chem. Solids.2008, 69(7), 1623-1631.

[16] Guo, D., Li, Y., Hu, C., Mao, L., nad Wang, E. Photocatalytic degradationof aqueous formic acid over the silica composite films based on lacunary Keggin-type polyoxometalates. Appl. Catal.2002, 235(1-2), 11-20.

[17] Mylonas, A., Papaconstantinou, E. On the mechanism of photocatalytic degradation of chlorinated phenols to $\mathrm{CO}_{2}$ and $\mathrm{HCl}$ by polyoxometalates J. Photochem. Photobiol A.1996, 94(1), 77-82.

[18] Hu, C., Yue, B., and Yamase, T. Photoassisted dehalogenation of organochlorine compounds by Para tungstate A in aqueous solutions. Appl. Catal: A.2000, 194-195 (1), 99-107.

[19] Papaconstantinou, E. Photochemistry of polyoxometallates of molybdenum and tungsten and/or vanadium. Chem. Soc. Rev. 1989, 18, 131.

[20] Kormali, P., Troupis, A., Triantis, T., Hiskia, A., Papaconstantinou, E. Catal. Today.2007, 124, 149.

[21] Zhang, S., Chen, L., Liu, H., Guo, W., Yang, Y., Guo, Y., Huo, M. Design of $\mathrm{H}_{3} \mathrm{PW}_{12} \mathrm{O}_{40} / \mathrm{TiO}_{2}$ and $\mathrm{Ag} / \mathrm{H}_{3} \mathrm{PW}_{12} \mathrm{O}_{40} / \mathrm{TiO}_{2}$ film-coated optical fiber photoreactor for the degradation of aqueous rhod amine B and 4-nitrophenol under simulated sunlight irradiation. Chem. Eng. J. 2012, 200-202, 300-309.

[22] Song, Y.-F., Tsunashim, R. Recent advances on polyoxometalate-based molecular and composite materials. Chem. Soc. Rev. 2012, 41, 7384-7402.
[23] Streb, C. New trends in polyoxometalate photoredox chemistry: from photosensitisation to water oxidation catalysis. Dalton Trans. 2012, 41, 1651-165.

[24] Wu, H. Contribution to the chemistry of phosphomolybdic acids, phosphotungstic acids, and allied substances J. Biol. Chem. 1920, 43, 189-220.

[25] Arendt, E., McEvoy, K.M., Gaigneaux, E.M. Structural rearrangement and catalytic properties of the Wells-Dawson $\left(\mathrm{NH}_{4}\right)_{6} \mathrm{P}_{2} \mathrm{Mo}_{18} \mathrm{O}_{62}$ heteropolycompound in the 2butanol reaction. Appl. Catal. A: General. 2009, 357, 115-124.

[26] Weiping, W., Shuijin, Y. Photocatalytic Degradation of Organic Dye Methyl Orange with Phosphotungstic Acid. Water Resource and Protection, 2010, 2, 979-983.

[27] Lan, L.W., Li, J., Chen, Q. Y. Photocatalytic Propertiesfor Photocatalytic Water Splitting of $\mathrm{H}_{4} \mathrm{SiW}_{12} \mathrm{O}_{40} / \mathrm{TiO}_{2}$. Nonferrous Metals, 2009, 3, 35-38.

[28] Trolliet, C., Coudurier, G., Vedrine, J. C. Influence of the nature and porosity of different supports on the acidic and catalytic properties of $\mathrm{H}_{3} \mathrm{PW}_{12} \mathrm{O}_{40}$. Topics in Catalysis, 2001, 15,(1), 73-81.

[29] Pope, M.T. Heteropoly and Isopolyoxometalates, Springer-Verlag, New York, 1983.

[30] Marcì, G., García-López, E., Palmisano, L., Carriazo, D., Martín, C., Rives, V. Preparation, characterization and photocatalytic activity of $\mathrm{TiO}_{2}$ impregnated with the heteropoly acid $\mathrm{H}_{3} \mathrm{PW}_{12} \mathrm{O}_{40}$ : Photo-assisted degradation of 2propanol in gas-solid regimeAppl. Catal. B: Environ.2009, 90, 497-506.

[31] Rocchiccioli-Deltcheff, C., Amirouche, M. Fournier, M. Frank, R. Structure and catalytic properties of silica-supported polyoxomolybdates III. 12-molybdosilicic acid catalysts: vibrational study of the dispersion effect and nature of the mo species in interaction with the silica support. J. Catal. 1992, 138, 445-456.

[32] Alexandru, P.,Viorel, S., Danica, B-B., Ivanka, H-A. J. Porous. Mater.2016, 23, 211.

[33] Giuseppe, M., Elisa, G-L., Vincenzo, V., Giuseppe, S., Diana S., Leonardo, P. Keggin 
heteropolyacids supported on $\mathrm{TiO}_{2}$ used in gassolid(photo)catalytic propene hydration and in liquid-solid photocatalyticglycerol dehydration. Catal. Today, 2017, 281, Part 1, 60-70.

[34] Biela'nnski, A., Datka, J., Gil, B., MałeckaLuba'nska, A., Micek-Ilnicka, A. Catal.Lett. 1999, 57, 61-64.

[35] J. Tauc, Optical properties and electronic structure of amorphous Ge and Si. Mater. Res. Bull. 1968, 3, 37-46.

[36] Sukriti, S., Anjali P. 12-Tungstophosphoric acid supported on mesoporous molecular material: synthesis, characterization and performance in biodiesel productionJournal of Cleaner Production 2014, 72, 46-56.

[37] Cuentas, A.K., Frausto, C., Ortiz-Frade, L.A., Orozco, G., Raman spectra of hybrid materials based on carbon nanotubes and $\mathrm{Cs}_{3} \mathrm{PMo}_{12} \mathrm{O}_{40}$. Vib. Spectrosc. 2011, 57, 49-54.

[38] Popa, A., Sasca, V., Kiss, E.E., MarinkovicNeducin, R., Holclajtner-Antunovic, I. Mesoporous silica directly modified by incorporation or impregnation of some heteropolyacids: Synthesis and structural characterization. Mater. Res. Bull. 2011, 46, 19-25.

[39] Brahmkhatri, V., Patel, A. Synthesis and Characterization of 12-Tungstosilicic Acid Anchored to MCM-41 as well as Its Use as Environmentally Benign Catalyst for Synthesis of Succinate and Malonate Diesters. Ind. Eng. Chem. Res. 2011, 50, 13693-13702.

[40] Guo, Y., Hu, C. Heterogeneous photocatalysis by solid polyoxometalates. J. Mol. Catal. A: Chemical.2007, 262(1-2), 136-148.

[41] Ai, M. Effects of cations introduced into 12molybdophosphoric acid on the catalyst properties. Appl. Catal. 1982, 4, 245-256.

[42] Akimoto, M., Shima, K., Ikeda, H., Echigoya, E. 12-Heteropolymolybdates as catalysts for vapor-phase oxidative dehydrogenation of isobutyric acid: 2. Group Ib, IIb, IIIb, and VIII metal salts. J. Catal. 1984, 86, 173.

[43] Mizuno, N., Misono, M. Catalytic oxidation and isotopic exchange of hydrogen over 12tungstophosphoric acid. J. Phys. Chem. 1989, 93, 3334.
[44] Kozhevnikov, I.V., Matveev, K.I. Homogeneous catalysts based on heteropoly acids. Applied Catalysis, 1983, 5, 135-150.

[45] Souchay, P. In Polyanions et polycations; Gauthier-Villars, Ed. 1963.

[46] Papaconstantinou, E. Photochemistry of Polyoxometallates of Molybdenum and Tungsten, and/or Vanadium, Chem. Soc. Rev. 1989, 16, 1.

[47] Saeid, F., Zaynab, B., Mansoureh, M. Sol-Gel Silica-Supported 12-Tungstosilicic Acid $\left(\mathrm{H}_{4} \mathrm{SiW}_{12} \mathrm{O}_{40} / \mathrm{SiO}=\right)$ as a Heterogeneous Photocatalyst for Efficient and Selective Oxidation of Benzylic Alcohols with O2 under Photoirradiation. Acta Chim. Slov. 2006, 53, 72-76.

[48] Papaconstantinou, E. Photocatalytic oxidation of organic compounds using heteropoly electrolytes of molybdenum and tungsten. J. Chem. Soc., Chem. Commun. 1982, 12-13.

[49] Hill, C. L., Bouchard, D. A. Catalytic photochemical dehydrogenation of organic substrates by polyoxometalates. J. Am. Chem. Soc. 1985, 107, 5148-5157.

[50] Nomiya, K., Sugie, Y., Miyazaki, T., Miwa, M. Catalysis by heteropolyacids-ix. Photocatalytic oxidation of isopropyl alcohol to acetone under oxygen using tetrabutylammonium decatungstate. Polyhedron. 1986, 5, 1267-1271.

[51] Yamase, T., Usami, T. Photocatalytic dimerization of olefins by decatungstate(VI), $\left[\mathrm{W}_{10} \mathrm{O}_{32}\right]^{4-}$, in acetonitrile and magnetic resonance studies of photoreduced species. J. Chem. Soc., Dalton Trans.1988, 183-190. 